\title{
Limites e Potenclalidades Da \\ GovernabILIDADE E DA GOVERNANÇA \\ Urbana: O CASO de Salvador
}

\author{
Anete Brito Leal Ivo* \\ Élvia Miriam Cavalcanti Fadul**
}

Florence Heber ${ }^{* * *}$

\section{Introdução}

globalização da economia tem afetado os limites institucionais de
responsabilidade do Estado brasileiro, tornando cada vez mais difí-
cil a execução de projetos de desenvolvimento macroeconômicos de âmbito nacional. Paralelamente, o processo de urbanização crescente ampliou as demandas de bens e serviços públicos impondo novos desafios aos municípios, que passam a se constituir no "locus" privilegiado da busca de soluções para esses desafios e para a implementação de políticas de desenvolvimento. A Constituição Federal de 88 procedeu as acomodações institucionais necessárias ao reavivamento da base local do poder público, ampliando as competências exclusivas e compartilhadas dos municípios brasileiros, particularmente no que se refere à responsabilidade de programas sociais.

Buscando associar democracia e maior eficiência do Estado, este novo modelo de regulação estatal apoia-se num esforço de fortalecimento do

* Mestre em Sociologia/UFBA

** Doutora pela Université Paris XII

**** Doutoranda em Administração/UFBA 
espaço público, potencializando alternativas inovadoras de gestão; multiplicando as possibilidades de participação de diversos segmentos sociais; ampliando as modalidades de comunicação entre eles e com as esferas institucionais do executivo municipal, sem desprezar os padrões de justiça social capazes de atenuar conflitos e enfrentar desigualdades sociais.

Nessa perspectiva, este trabalho analisa algumas experiências de governança urbana ${ }^{2}$ reveladoras da capacidade de inovação de práticas de gestão que incorporam a participação da sociedade civil no processo decisório, a partir de experiências da Prefeitura Municipal de Salvador, no período de 1993-1996. Vinculada ao PSDB durante o período 1993-1996, enquanto a hegemonia da gestão democrática no país vem sendo exercida, tradicionalmente, pelo PT, a Prefeitura de Salvador apresenta condições singulares de gestão que constituem, não somente, um caso especialmente rico e significativo para o debate dessas questões, como uma experiência relevante para qualificar limites e potencialidades da governança urbana.

A partir de estudos acerca do planejamento urbano e do orçamento participativo, que recuperam experiências de gestão de caráter mais global e de uma experiência exitosa, descentralizada e setorial que é a profissionalização do Camaval, evento de grande impacto na área da produção turística e cultural da cidade, procurou-se avaliar o processo de governança, seus limites, contradiçōes e possibilidades. Procurou-se, através dessas experiências, apreender e descrever o tecido mediador das relaçōes entre o executivo e a sociedade no formato participativo ou consubstanciado no funcionamento de Conselhos e na institucionalização de um conjunto de convenções, regras e redes hierarquizadas. As análises procuraram captar a capacidade efetiva de defender interesses coletivos na inversão de prioridades e apontar alguns resultados de políticas, avaliando até que ponto os instrumentos utilizados foram ou não suficientes para a universalização de processos democráticos e para a consolidação do espaço público.

Algumas questões básicas orientaram as análises, quais sejam: quais foram as condiçōes efetivas da governança urbana, seus maiores desafios e entraves? Como este processo se articulou com a descentralização administrativa e a regulação da cidade? Que alternativas inovadoras foram geradas e implementadas no sentido de potencializar a participação de forças sociais e políticas e fortalecer a relação democrática com a sociedade civil? 
Limites e Potencialidades da Governabilidade e da Govemança Urbana: O Caso de Salvador

\section{Planejamento Urbano, Plano Diretor e Governança}

Para analisar os processos de governança efetivamente implementados a partir da experiência do planejamento e da revisão do PDDU, procurouse examinar: a base institucional existente para a implantação das novas estruturas de governança; as condiçôes operativas do sistema de planejamento e os canais mediadores da participação, observando os novos elementos de intervenção pública utilizados e avaliando a capacidade de articular - democratização, com eficiência e redução das desigualdades sociais e econômicas.

Algumas dificuldades institucionais se apresentaram desde o início do governo, no que se refere ao planejamento municipal. $O$ órgão central de planejamento daquela época, o CPM (Centro de Planejamento Municipal) só teve o seu presidente nomeado dois meses depois de instaurado o governo. Este fato, aparentemente operacional não é irrelevante nesse contexto e se desdobra, a seguir, numa tensão constante entre CPM e executivo municipal, revelando o significado político que a função planejamento teve nessa gestão. Procurando marcar diferenças entre as noções de planejamento e plano diretor, o executivo municipal restringe a competência administrativa regimental do CPM apenas ao planejamento urbano e à elaboração do PDDU. A falta de clareza quanto ao caráter político e estratégico do órgão central de planejamento na definição de políticas, aliada à incapacidade de definir, a curto prazo, um programa de governo ${ }^{3}$ acabam por criar contradiçōes entre o executivo municipal e o presidente do CPM que, finalmente, culminaram no afastamento deste último do cargo, em fevereiro de 1994, um ano depois de sua nomeação.

As dificuldades enfrentadas desde o início do governo na montagem de um sistema de planejamento e elaboração do novo Plano Diretor explicitam dos limites entre as funções de governabilidade ${ }^{4}$ (direção e comando do governo municipal) e as instâncias da governança (envolvendo participação e cooperação internas e externas à prefeitura) as quais acabaram por resultar na própria indefinição do PDDU, concebido como instrumento básico de política urbana pactuada entre os diferentes agentes públicos e privados.

Completando esse quadro de tensão interna, desenvolvia-se, paralelamente, às açōes do CPM, o Programa de Desenvolvimento de Açōes 
Estratégicas (PRODAE), criado neste governo e vinculado diretamente ao Gabinete do Prefeito. O objetivo fundamental desse programa era a implantação de um Programa de Qualidade-Total para a administração municipal, envolvendo a modernização do aparato burocrático através da sensibilização e da capacitação dos servidores. A implantação desse Programa de Qualidade requeria uma definição de diretrizes de governo o que resultou, finalmente, na montagem de um processo de planejamento das ações do executivo, realizado pelo PRODAE, sob estreita supervisão do prefeito. Essas diretrizes se transformam, mais tarde, em referencial para a montagem do Planejamento Estratégico da Cidade de Salvador, inspirado no Plano Estratégico de Barcelona.

Essas estruturas paralelas e superpostas criaram ainda mais tensão no plano operacional e político, comprometendo a eficiência da máquina administrativa e fomentando desacordos internos nas equipes. Os ajustes nesse desenho institucional ocorreram no final de 1994 com a criação da Secretaria de Planejamento e Desenvolvimento Econômico - SPDE que só veio ser implantada, efetivamente, no final de 1995, incorporando o antigo CPM e a Superintendência de Controle e Ordenamento do Uso do Solo do Município - SUCOM, unificando as funções de planejamento, orçamento, controle do uso e ocupação do solo, desenvolvimento econômico e modernização administrativa. Ao lado dessa estrutura conflituosa, de superposição de competências, o executivo inicia a implementação efetiva das 17 Administrações Regionais (ARs), sem o estabelecimento prévio de acordos quanto aos limites de competência e sem uma adequada compatibilização das ações de desenvolvimento urbano, comprometendo ainda mais as condições de governança urbana da cidade.

\section{Os arranjos mediadores de articulação de interesses}

O modelo de Planejamento Estratégico adotado em Salvador procurou reafirmar o processo flexível de descentralização que facilitou a implementação de diversas modalidades participativas, estabelecendo instrumentos e regras de negociação dos interesses do poder público, dos agentes econômicos e da sociedade para o desenvolvimento de projetos. Procurando superar a concepção tradicional de planejamento a longo prazo e valorizar uma estrutura mais flexível e de curto prazo, as intervenções 
Limites e Potencialidades da Governabilidade e da Governança Urbana: O Caso de Salvador

desse modelo de planejamento apresentaram-se em três formatos: a) um nível de intervenção de impacto mais localizado, de recuperação de praças e pequenas melhorias urbanas, inseridas ou não em projetos mais ambiciosos de renovação urbana e de dinâmica metropolitana; b) um outro nível de intervenção de caráter prioritário, envolvendo um projeto de urbanização e medidas emergenciais em áreas urbanas de periferia; e c) uma macro-intervenção avançando o processo de reurbanização da Orla Atlântica da cidade.

As micro-intervenções usaram o instrumento da contrapartida, caracterizado pela troca do benefício concedido pelo município ao setor privado na forma de autorização de índices urbanísticos em caráter excepcional, por serviços e obras públicas. Para os projetos prioritários encaminhados por entidades representativas das comunidades locais para a urbanização de bairros populares de periferia, de ocupação recente e irregular, ${ }^{5}$ três tipos de mediação foram utilizados: a) a parceria comunitária, firmada em convênio entre a prefeitura e instituições comunitárias; b) a formação de uma comissão intersetorial ${ }^{6}$ visando a implantação de programas de urbanização de bairros populares; c) a formação de Termo de Acordo e Compromisso com os proprietários de terras na invasão das Malvinas (Bairro da Paz) para delimitação de área, urbanização e titulação dos ocupantes.

Um outro instrumento amplamente utilizado foi a mobilização de agentes privados em parceria na execução de obras ou de melhorias necessárias à renovação e ao convívio urbanos. Embora de proporções limitadas, estas iniciativas produziram resultados de curto prazo que se constituíram em alternativas concretas para enfrentar a limitação de recursos financeiros para investimento em infra-estrutura reduzindo, em parte, a degradação de alguns espaços públicos da cidade. Ao lado dessas ações partilhadas a prefeitura procurou mobilizar a comunidade em torno da formulação de programas de revitalização e reurbanização de áreas antigas e tradicionais da cidade ${ }^{7}$, criando comissões representativas dos diversos interesses nas quais prefeitura e sociedade cooperaram na definição de prioridades e na construção de soluções.

\section{Padrões de articulação e cooperação alcançados}

Frente a essas ações, importa saber se, por um lado, o modelo flexível de descentralização adotado (via macro ou micro-intervençōes espaciais) constituiu-se em instrumento de eficácia e fortalecimento das regras de- 
mocráticas e quais são seus limites? E, por outro lado, indagar até que ponto o direito à participação, instituído por esses instrumentos de negociação criou uma nova consciência cívica nos atores mobilizados?

A flexibilização do planejamento urbano através desses programas representou, de fato, um instrumento importante para a mobilização de diversos agentes sociais e econômicos, estimulando a ética da co-responsabilidade entre parceiros e aliados. No entanto, sem a definição clara de competências institucionais e de um projeto mais amplo para a cidade sua implementação teve, em alguns casos, efeitos perversos, tanto no plano da administração como no plano das externalidades.

No nivel administrativo esta indefinição criou espaços de tensão entre a instância de comando do governo e a esfera de implementação de projetos urbanos e dessas com as unidades executoras das ações regionalizadas, especialmente com as ARs. No âmbito das externalidades, a superposição dos vários agentes mobilizadores, além da incapacidade de dar respostas imediatas às demandas mais ambiciosas emanadas da mobilização popular, constituiu-se em elemento desmobilizador e deslegitimador das ações da prefeitura expressando, ainda mais, a face de inoperância que desgastou a imagem pública. A participação social circunscrita a pequenos pactos e a parcerias em arenas restritas constrangeu o processo democrático mais amplo e reduziu sua capacidade de definir prioridades e hierarquizar ações, remetendo as decisões ao âmbito do governo.

As contradições que já se expressavam no âmbito de alguns dos grandes projetos, especialmente em áreas de expansão urbana onde se defrontam interesses opostos do setor imobiliário e do movimento ambientalista ou, entre o comércio informal (vendedores ambulantes) e os setores comercial e imobiliário, parecem ter atuado como fatores inibidores de uma política mais ampla e decisiva de regulação urbana. Efetivamente, os compromissos do chefe do executivo municipal com os movimentos populares e com a população carente inserida, em sua grande maioria, no setor informal, concorreu para definir um perfil de ação que procurava evitar políticas anti-populares ou confrontos explícitos com diversos segmentos sociais, evitando expor o governo a confrontaçōes mais amplas. Por isso, as diversas estruturas participativas implementadas forjaram um modelo de cooperação linear constrangido que viabilizou a cooperação, a negociação e o consenso restritos, sem contudo, conformar um tecido interarticulado, ca- 
Limites e Potencialidades da Governabilidade e da Governança Urbana: O Caso de Salvador

paz de forjar redes solidárias amplas e criar dimensões políticas mais universais para a cidade, necessárias ao aprofundamento do processo democrático. Faltou, ainda, um projeto de desenvolvimento mais estruturante $\mathrm{e}$ de longo prazo para a cidade e a institucionalização de novos instrumentos de regulação capazes de enfrentar as desigualdades e a segmentação do espaço urbano. Faltou, também, uma mobilização mais efetiva da política local e do próprio Conselho de Desenvolvimento Urbano.

Não se pode, no entanto, negar o êxito de algumas dessas iniciativas na formação de uma nova consciência do empresariado local - parceiro maior no desenvolvimento dos projetos urbanísticos - e na formação de uma nova ética de co-responsabilidade na relação entre o público e o privado. Este processo, porém, contém uma dimensão perversa ao privilegiar setores e/ou segmentos urbanos sem dúvida legítimos mas questionáveis quanto ao seu caráter prioritário, por não estarem submetidos aos critérios definidos pelo planejamento estratégico da cidade.

\section{Alguns constrangimentos experimentados}

Crucial na análise da eficácia de um governo é a sua capacidade de implementação de políticas. Esta capacidade é condicionada por fatores financeiros, por fatores políticos e por limitações operacionais da estrutura burocrática do aparato municipal. São por demais conhecidas as restrições de recursos dos municípios brasileiros, ampliadas pela conjuntura de ajustes do Plano Real. No âmbito político, o Plano Estratégico não sensibilizou nem comprometeu a sociedade nem os políticos, ficando restrito aos Secretários e dirigentes das autarquias municipais, por força do programa de Qualidade-Total mas sem articulação nem consenso em espaços políticos mais amplos, capazes de enriquecer o debate institucional e legitimar o processo.

Por outro lado, parecem existir dificuldades resultantes da própria natureza da prática da esquerda. Provavelmente, aí se localiza um dos fatores mais importantes do alcance do planejamento neste governo. Na realidade, a necessidade de reverter a visão generalizada de que "a esquerda não sabe ser governo, sabe criticar mas não sabe fazer ou realizar", pode ter aprofundado o clássico dilema entre produzir resultados e desenvolver uma auto reflexão sobre o plano. Além disso, observa-se nesta conjuntura, uma certa dificuldade da esquerda em pensar projetos mais estruturantes, de longo prazo. Prova disto foi a falta 
de visão política do significado estratégico do próprio plano, como instrumento fundamental do governo na formulação de um projeto consistente de desenvolvimento econômico, com justiça social. Esta dificuldade parece ser responsável pela dicotomia entre ofazer e o pensar; entre os processos de participação na ponta do sistema e a centralização das tomadas de decisão.

Junta-se a isto, a competência relativa dos membros desta equipe para governar a cidade, muito mais assentada na experiência parlamentar do que na capacitação gerencial. Nesse aspecto, parecem ter ocorrido dois equívocos: o primeiro, situa-se na pouca incorporação das equipes de trabalho existentes, privilegiando-se uma assessoria nova que, embora competente, carecia de maior vivência do sistema; o segundo, refere-se ao pouco uso dos mecanismos de intermediação existentes em estruturas colegiadas como o CONDURB (Conselho de Desenvolvimento Urbano) que poderiam ter facilitado a mediação e legitimação das açōes do órgão de planejamento, no plano político. No âmbito da capacidade interna do sistema de planejamento observa-se, ainda, que o pequeno acervo de informações atualizadas limitou a instrumentalização do processo decisório e de regulação no sentido de um alcance mais democrático da própria informação, tanto para utilização de agentes públicos como privados.

Por fim, vale ressaltar que, fatores políticos como o confronto entre o executivo municipal e o governo do Estado, a falta de apoio do governo federal no período posterior a 1995 e a fragilidade da aliança eleitoral imprimiram uma atitude política cautelosa, voltada para a busca de um consenso, construído através de dois mecanismos: a) da obtenção de solidariedades em acordos parciais com inúmeras esferas do tecido social (empresários; movimentos sindicais, de bairro e pela cidadania); e, b) de uma estratégia de evitar confrontos explícitos com grupos políticos e setores sociais. Se por um lado esta estratégia, combinada com uma democratização nas bases, garante à municipalidade um relativo grau de autonomia, por outro lado, restringe o alcance político dos novos instrumentos.

\section{O Orçamento Participativo}

Os esforços para a formação de redes de interação com segmentos da sociedade, para a institucionalização de instrumentos de participação e para 
a transformação dos modelos tradicionais de gestão da cidade expressamse, também, nas tentativas de implantação de um processo de elaboração orçamentária de cunho participativo.

Salvador, como outras capitais brasileiras, se defrontou com as mesmas dificuldades administrativas e financeiras advindas dos processo de descentralização e autonomia dos municípios e da reforma tributária, sofrendo um pouco mais, por conta de um processo de descontinuidade administrativa intenso entre 1975 e 1989. Desse modo, os desajustes financeiros encontrados hoje, no município, decorrem, em parte, de um desequilíbrio estrutural das finanças públicas, mas de outra parte, de acordos políticos mas encetados em mandatos anteriores, cujos desfechos comprometeram a gestão da cidade (seqüestro das verbas) ${ }^{8}$.

Com isso, as finanças do município apresentaram, no período 1993. 1996, um panorama contraditório. Pode-se dizer que sua arrecadação cresceu, efetivamente, mas a diminuição das transferências negociadas (transferências livres do tesouro estadual ou federal) e as proporçōes assumidas pelo endividamento ${ }^{9}$ obrigaram a cidade a se financiar com empréstimos de curto prazo, em contratos firmados com diferentes bancos, dificultando a renegociação das dívidas e a obtenção de empréstimos de longo prazo.

A conjuntura de desajuste político (interno e externo) e de crise fiscal num municipio populoso (2.472.937 habitantes) como Salvador, com altos índices de pobreza e baixa capacidade de poupança vai pôr em risco as pretensões de instaurar, enquanto mecanismo de gestão democrática apresentado durante a campanha eleitoral, as bases para a montagem de um processo de elaboração do Orçamento Participativo.

\section{O formato institucional do processo decisório: atores relevantes e esferas de poder}

No plano institucional, a elaboração do orçamento era feita no CPM em articulação com a Secretaria Municipal de Governo (SEGOV) e a Secretaria da Fazenda. Com a reforma administrativa tardia e a criação da Secretaria Municipal de Planejamento e Desenvolvimento Econômico, procurou-se articular planejamento estratégico e orçamento através da CEPRO (Coordenação Central de Programação e Orçamento) subordina- 
da ao Secretário de Planejamento e Desenvolvimento Econômico. A condução do processo de orçamento participativo é de responsabilidades das ARs, sob a coordenação da Coordenadoria das Administrações Regionais (vinculada à SEGOV) mas é a Secretaria das Ações Municipais a unidade articuladora central do processo do Orçamento Participativo. Cada AR tem um administrador, de livre escolha do prefeito e vários articuladores comunitários escolhidos pelo Conselho representativo da respectiva região, para um mandato de 2 anos. As ARs não são unidades orçamentárias nem unidades gestoras descentralizadas, não têm autonomia orçamentária, financeira e administrativa, nem se constituem em sub-prefeituras com capacidade administrativa e competência gerencial.

O processo de elaboração do orçamento participativo começa pela consulta popular em reuniões preparatórias abertas ao público (Plenárias temáticas) realizadas pelas Administraçōes Regionais, nas sedes das Associações de Bairro ou em outros espaços cedidos pela comunidade local, com a participação da população de setores profissionais e entidades de classe, juntamente com os Secretários Municipais e a equipe de orçamento da CEPRO. A Coordenação das ARs distribui questionários para as solicitações que são, em seguida, compatibilizados pela AR correspondente e encaminhados a uma Comissão que avalia a viabilidade das solicitações, observando critérios de custo/benefício, técnicos de execução, vinculação ao Planejamento Estratégico e ao Orçamento Plurianual de Investimentos. Definidas as prioridades, as indicações populares são encaminhadas aos Secretários responsáveis pelo atendimento das demandas, para incluílas nas suas respectivas propostas orçamentárias. Por fim, a Secretaria Municipal de Planejamento e Desenvolvimento Econômico consolida e sistematiza as propostas dos órgãos da administração municipal com aquelas provenientes das reuniões do Orçamento Participativo, ajustando-as à legislação.

O processo de execução do orçamento participativo, no entanto, não ganha impacto nas instâncias representativas do legislativo, nem é absorvido como espaço de debate pela Câmara Municipal. É possível que o desalinhamento entre o Partido dos Trabalhadores (que tem sustentado, doutrinariamente, o processo de orçamento participativo em outras cidades) e o chefe do executivo local ocorrido no início do mandato, tenha sido um dos primeiros motivos da falta de apoio dessa instância representativa 
Limites e Potencialidades da Governabilidade e da Governança Urbana: O Caso de Salvador

formal, à institucionalização desse processo, deixando de reconhecer e legitimar o novo espaço aberto à participação popular.

Por outro lado, razōes históricas mais gerais podem ter, também, de alguma forma, afetado o posicionamento do legislativo nesse processo participativo. O processo de elaboração dos orçamentos públicos no Brasil, nas três esferas de governo tem sido, tradicionalmente, de competência do poder executivo. A representatividade do poder legislativo manifesta-se na discussão, votação e aprovação do projeto de lei orçamentária. A Constituição Federal de 88 restabeleceu, com certas limitações, a capacidade do Poder Legislativo de participar do processo de elaboração orçamentária, através da proposição de emendas ao Projeto de Lei no que se refere às despesas. A abertura desse novo espaço de representatividade, pela via da participação popular na decisão quanto à alocação de recursos, concede legitimidade ao Executivo dispensando, de certa forma, a representatividade formal do legislativo.

Dentro desta lógica, o orçamento participativo pode ser, social e politicamente, um elemento de democratização e equidade social mas, no âmbito institucional, vai interferir, fundamentalmente, em três áreas sensíveis: a) aquela da competência técnica e da racionalidade dos processos de avaliação dos órgãos do poder executivo responsáveis pela elaboração orçamentária; b) aquela do processo decisório que ocorre dentro de cada uma das funções de governo (Secretarias Municipais) em termos da definição de políticas e prioridades relativas ao "interesse coletivo"; e, finalmente, c) aquela relativa às prerrogativas de representatividade do legislativo, criando um tipo de competição deste com a nova instância de decisão dos interesses comunitários.

Cabe aqui indagar, até que ponto o orçamento participativo, que nasce da necessidade de fortalecimento de uma relação democrática com a sociedade civil, pode ser considerado um novo modelo decisório, assentado na opinião popular e, até que ponto os resultados deste processo podem ser harmonizados com o processo técnico e político de elaboração e aprovação do projeto de lei orçamentária? Como encontrar a consistência necessária para a execução de um programa de políticas públicas eficiente e eficaz, na medida em que as propostas nascidas dos anseios populares não se encontram respaldadas na tomada de consciência crítica dos problemas no seu conjunto, dos mecanismos para 
enfrentá-los e do conhecimento adequado do funcionamento das organizações competentes para a sua realização?

A análise dessas zonas de conflito no processo de elaboração do Orçamento Participativo na cidade de Salvador permitiu identificar alguns dos entraves à sua implementação e fornecer os elementos necessários à percepção do grau de sucesso/insucesso que esta experiência obteve ao longo dessa gestão municipal, onde as condições tanto de governabilidade quanto de governança urbana se viram fortemente ameaçadas.

\section{A dimensão técnica}

A criação de espaços institucionais de participação com maior atenção às demandas populares envolve uma dimensão técnica. Os mecanismos e instrumentos que viabilizam a cooperação, a negociação e a busca do consenso são os recursos humanos e técnicos dos governos locais e, em geral, a questão técnica tende a sobrepujar, necessariamente, a manifestação popular, posto que as propostas têm que passar por uma análise de viabilidade que pode desvirtuar as solicitações originais.

Esse componente técnico é bastante reforçado nessa gestão, deixando transparecer que o processo de orçamento participativo foi instaurado, apenas, por força doutrinária de ideais de governos de esquerda (proposta de campanha) e como forma de mobilizar as camadas mais populares no apoio à administração. De fato, nas mensagens do executivo e nos documentos de planejamento, o instrumento de orçamento participativo não tem a centralidade estratégica capaz de propiciar uma inversão real de prioridades na ação governamental.

O objetivo maior desta administração no aprimoramento do processo de elaboração do orçamento municipal foi transformá-lo em um instrumento de planejamento, gestão e autonomia municipal, com um enfoque exclusivamente técnico. ${ }^{10} \mathrm{~A}$ descentralização administrativa enquanto estratégia para expansão e melhoria da qualidade dos serviços públicos e como forma de assegurar a participação política não aparece, com transparência, nos documentos desse governo. Isso revela que a execução do orçamento participativo não se constituiu num elemento estratégico central no modelo de gestão deste mandato, indicando um descompasso entre as propostas e as realizações do governo. Ao mesmo tempo que apresenta um 
discurso social, participativo, de flexibilidade e descentralização no que se refere ao orçamento, procura reforçar os mecanismos tradicionais de planejamento e elaboração orçamentária, sem contudo criar instrumentos correspondentes de supervisão e controle próprios desse tipo de modelo. Nesse campo, o Executivo Municipal procurou criar um espaço democrático e participativo no discurso, mas terminou por adotar um estilo de governo conservador.

\section{A dimensão política}

A elaboração do orçamento possui, também, um componente político para garantir eficiência e eficácia na implementação das políticas públicas. Nesse processo de orçamento participativo não houve, necessariamente, cooperação nem consenso por parte do Secretariado Municipal e, sim, uma resistência dos órgãos da administração, em proceder aos ajustes requeridos entre seus programas e as demandas populares. Muitos secretários consideravam o orçamento apenas uma exigência legal e uma peça de ficção a mais, dentro da burocracia pública.

A ausência de uma relação mais estreita entre o planejamento e o orçamento e a resistência generalizada e fragmentária do secretariado, criaram bloqueios à implementação desse instrumento de democratização do poder político. Nesses termos, a experiência de orçamento participativo não envolveu, necessariamente, um efetivo processo de descentralização de decisōes. Após a consulta às ARs, o projeto de lei do orçamento continuava a ser montado em bases tradicionais, sem vinculação com os planos de governo, não sendo utilizado enquanto instrumento de planejamento $\mathrm{e}$ administração pelos órgãos do poder executivo.

\section{A dimensão da representatividade}

Um dos grandes espaços históricos de conflito entre os Poderes Executivo e Legislativo é a área orçamentária. A função básica do Legislativo é manter o equilíbrio entre os poderes, limitando a exacerbação do exercício de poder por parte do Executivo. Contudo, o papel fiscalizador da instância parlamentar tem sido, em muitos municípios, anulado ou desvirtuado. Nesses termos, a criação de canais institucionalizados de intermediação 
entre sociedade e poder públ: co no processo de alocação de recursos públicos, representa uma disturção da fórmula tradicional de elaboração dos orçamentos públicos locais, na medida em que a participação do Legislativo "ficaria obscurecida pela atuação de uma nova instância de representação dos interesses sociais e comunitários" (Giacomoni, 1993). O autor considera que a prática do orçamento participativo evidencia uma dupla subversão da técnica tradicional de elaboração orçamentária. A primeira, no momento em que substitui o racionalismo técnico da burocracia governamental por um racionalismo substantivo ou valorativo surgido da participação dos atores sociais envolvidos e a segunda, quando concede legitimidade às intenções do Executivo através da representatividade popular, prescindindo da participação do legislativo.

\section{Problemas e entraves no processo participativo}

$\mathrm{Na}$ realidade, a ordem de grandeza do orçamento participativo é limitada. Isso significa dizer que, numericamente, o orçamento participativo resume-se, apenas, a dividir corretamente o que sobra, depois de definidos os valores referentes ao custeio, serviço da dívida e investimentos estratégicos da administração. Sendo os pleitos superiores aos recursos disponíveis, esses recursos que sobram são sempre escassos para fazer frente às necessidades. Os recursos destinados ao orçamento participativo para 1997, em Salvador, representam $27 \%$ do total dos recursos para investimentos que são da ordem de $10 \%$ do Orçamento global do município.

Enfim, a maior limitação que pode vir, realmente, a comprometer esse espaço de relação entre governantes e governados, aberto em Salvador nesta gestão é não se ter criado um lastro institucional mais amplo, capaz de sustentar o processo participativo de elaboração orçamentária. Não foi instituído um mecanismo sólido capaz de apoiar e dar continuidade a esse processo, que pode ser desmantelado a qualquer momento. Em grande medida, porque a participação da comunidade não teve um peso institucional importante nesse procesșo. O governo local concedeu o direito mas não criou condiçōes mais amplas para a conquista deste direito e a garantia da sua continuidade, de forma que a expressão participação popular, freqüentemente utilizada para se referir aos movimentos associativos e reivindicativos de grupos sociais de baixa renda, excluídos das decisões e 
Limites e Potencialidades da Governabilidade e da Governança Urbana: O Caso de Salvador

do controle dos recursos se transforme, realmente, na conquista de um espaço de participação da comunidade e num processo de aperfeiçoamento da prática democrática.

Ainda que incipiente, este processo teve, sem dúvida, sua contribuição positiva na ampliação de um espaço político, incorporando valores de democracia em determinados segmentos sociais, a partir da construção de uma consciência de cidadania. Mas, finalmente, a busca do consentimento de grupos organizados, constituiu-se numa tentativa de alcance limitado de aperfeiçoamento de práticas democráticas e de criação de um modelo decisório inovador terminando, apenas, por garantir legitimidade, dividir responsabilidades e fracassos e atender, minimamente, às demandas e necessidades sociais locais.

\section{O Conselho Municipal do Carnaval}

O Carnaval de Salvador é multifacetado, é a complexidade das complexidades. Combina cada vez mais o lúdico ao negócio, o essencialmente local ao potencialmente transnacional, o puramente anárquico à anarquia organizada, sob a égide de uma intensa dinâmica de transformação. Produto sem paralelo no mercado de lazer e diversão, o Carnaval baiano é negócio para todos: as organizaçōes carnavalescas, o trade turístico, o comércio, o setor público, os empresários, produtores e músicos, a área informal. $O$ carnaval é altamente redistributivo e envolve o trabalho direto de cerca de 50 mil pessoas (Costa, 1996).

Este cenário requisitava, cada vez mais, o desenvolvimento de novos arranjos organizativos, capazes de articular múltiplas lógicas e atores, especialmente no campo institucional público e das organizações privadas, viabilizando a cooperação, a negociação e a busca de ações concertadas. Esse processo de potencialização das ações se deu nesta gestão municipal de 1993-1996, correspondendo a alterações no planejamento e gerenciamento da festa, através de ação conjunta da prefeitura e do Conselho Municipal do Carnaval, órgão colegiado, representativo das várias organizações que participam do carnaval. Nesses termos, a profissionalização do Carnaval, com destaque para o desempenho do Conselho, surge como uma experiência exitosa de governança urbana nesta gestão municipal. 


\section{Princípios e regência da ação concertada}

Em 1989 Conselho Municipal do Carnaval é criado pela Lei Orgânica do município de Salvador, como um órgão colegiado e representativo de entidades, de órgãos públicos e da sociedade, com atribuições fiscalizadora e deliberativa. O Coordenador do Carnaval, eleito pelo Conselho com um mandato de um ano, é também membro deste, enquanto representante de um dos segmento com assento no Conselho. Entretanto, o desempenho deste arranjo institucional revelou-se frustrante nos primeiros anos. $\mathrm{O}$ Conselho praticamente só se reunia para eleger o Coordenador do Carnaval, que assumia sozinho todas as atribuições, reproduzindo a estrutura de poder personalista e dependente do ocupante do cargo. Os atritos com a prefeitura eram inevitáveis e, de todo modo, a administração municipal neste período (1989-1992) não dispunha de qualquer projeto mais consistente para o evento.

Considerando o Carnaval como uma das prioridades de governo, a gestão municipal que assume em 1993, dentro de seus compromissos de campanha de propiciar a participação de atores sociais locais no processo decisório de governo da cidade, procura de um lado, estabelecer determinados princípios gerenciais para a busca da profissionalização do Carnaval visto como principal produto turístico e cultural da cidade e, por outro, consolidar fóruns permanentes de discussão e deliberação acerca dos rumos que definiriam toda a organização da festa. Nesta concepção, a possibilidade de introduzir na gestão pública métodos e procedimentos administrativos orientados para a eficácia dos resultados articulava-se com a necessidade de estabelecer novas bases de interlocução - com e entre - os diversos atores do carnaval, restringindo o espaço de influências personalistas e clientelistas, ao tempo em que proporcionava a montagem de um esquema de cooperação, negociação e busca de consenso, além de garantir um aporte significativo de informações sobre os meandros da festa.

Para dar suporte às ações de caráter propriamente gerencial foi criada a Casa do Carnaval, que passou a centralizar as ações e decisões concernentes ao evento, reunindo a memória técnica e documental em banco de dados, além de formar e abrigar uma geração de profissionais do carnaval, entre arquitetos, administradores, engenheiros e economistas (Costa, 1996). Além de abrigar o Núcleo Técnico e a Comissão Especial 
do Carnaval, a Casa do Carnaval passou também a ser sede do Conselho Municipal do Carnaval e da Coordenação do Carnaval.

De acordo com Costa (1996), alguns pressupostos conceituais norteavam as políticas direcionadas ao Carnaval: a) a profissionalização deve preservar o brilho, a espontaneidade e a animação como marcas essenciais do carnaval; b) o setor público deve reduzir sua participação no financiamento do carnaval, captando patrocínios para custeio do aparato infra-estrutural e estimulando a auto sustentação das entidades dependentes de apoio; c) o empresariado deve emergir como o grande financiador do Carnaval, em contrapartida às oportunidades de consumo maciço de seus produtos e serviços facultadas pela festa.

O redirecionamento gerencial operado pela prefeitura, no sentido de garantir a profissionalização dos procedimentos de realização do evento, exigiu do Conselho uma nova postura. Nas palavras do então Presidente da Casa do Carnaval, "o Conselho teve que melhorar a sua qualidade, inclusive porque a prefeitura passou a imprimir um novo ritmo, passando a levar uma série de decisões para o Conselho se pronunciar, ser mais atuante, representar aquilo que as entidades têm a oferecer. Isso modificou, inclusive, a qualidade das representações com a mudança de alguns representantes anteriores".

A mudança de postura do Conselho se fez sentir, inclusive, na regularidade do seu funcionamento, passando a reunir-se semanalmente, durante todo o ano. Por outro lado, a Câmara Municipal teve um papel intenso nos primeiros anos desta gestão, promovendo debates sobre temas como o espaço físico, estruturas tubulares, descentralização do carnaval, infra-estrutura da festa, produção e co-produção, licitações e contratações de serviços, orçamento geral, auto financiamento e projeto do carnaval/94. As conclusóes dos debates na Câmara eram analisadas e deliberadas nas reuniōes do Conselho do Carnaval e posteriormente encaminhadas à prefeitura.

\section{O conselho do carnaval: escopo e artífices}

O papel do Conselho na estruturação do carnaval foi fundamental na medida em que permitiu, organizadamente, uma interlocução regular dos vários setores envolvidos na festa com os canais de decisão da prefeitura. Tornou-se um fórum significativo ao articular os vários setores e os órgãos públicos que prestam serviços essenciais ao carnaval, garantindo bases 
operacionais para a realização do evento e atuando, do ponto de vista político, como facilitador na resolução de conflitos entre todos os segmentos do carnaval.

Reunindo organizações que vão desde aquelas mais formais e estruturadas àquelas de desenho mais leve, informais e flexíveis, o Conselho tornou-se, também, o fórum representativo de interesses diferenciados subjacentes à festa, nele estando representadas: a) organizações públicas executivas, regulamentadoras, fiscalizadoras e outras de produção de serviços coletivos das três instâncias de governo; b) organizações empresariais de significativo poder econômico, como é o caso das associações de blocos de trio, as de proprietários de som e iluminação e as de clubes sociais; c) organizações mais tradicionais do Carnaval baiano, cujo conteúdo agregador é a produção de cultura popular negro-mestiça, como é o caso dos afoxés, dos blocos afro, blocos de índio e blocos de percussão; d) as associaçōes e sindicatos que representam categorias profissionais, tais como as dos barraqueiros de festas populares, vendedores ambulantes e feirantes de Salvador, artistas plásticos, músicos e cronistas carnavalescos.

Como há uma grande desproporção entre as organizações que compõem o Conselho, algumas com um ínfimo número de associados, outras mais pesadas e bem estruturadas, com interesses muito bem definidos, algumas representaçōes acabam tendo maior poder de decisão. E o choque de idéias tem, cada vez mais como pano de fundo, os interesses econômicos em jogo. No entanto, as bases sob as quais se assentaram as negociações entre a prefeitura e o Conselho, revelaram-se bastante eficientes. Em primeiro lugar, o reconhecimento da autonomia do Conselho funcionou como um elemento catalisador de posturas mais conscientes e consistentes na reflexão e decisão sobre os rumos do Carnaval. Por outro, a criação, pela prefeitura, de estruturas técnicas e gerenciais eficazes, garantiu uma interlocução de alto nível. O processamento de informaçōes as mais variadas possíveis, desde plantas de circuitos à estimativas de público em determinados locais e horários, deu respaldo às propostas apresentadas pelo governo municipal.

Admite-se, hoje, a necessidade de reformulação no Conselho. Criado numa época (logo após a Constituição de 88 ) em que todos os ventos sopravam a favor da institucionalização de instrumentos promotores da democracia e participação social, o Conselho permanece, de certo modo, 
refletindo na sua operacionalidade, apenas os ideais daquele período. $\mathrm{Na}$ visão de técnicos da Casa do Carnaval, apesar do Conselho ser muito positivo para a cidade, ele precisa se renovar, precisa dispor de equipamentos e pessoas tecnicamente preparadas para produzir informações e documentos que consubstanciem as suas tomadas de decisão; criar arquivos e informações sobre cada segmento que atua no Carnaval; sobre o próprio Carnaval, seus circuitos, economia da festa, infra-estrutura, planejamento etc.

Enquanto a necessidade de reforma e modernização do Conselho mobiliza discussões por um lado, por outro, são colocadas enormes dúvidas quanto à sua sobrevivência no futuro. De todo modo, parece que estas questões estão intimamente articuladas. Com a chegada da nova gestão municipal, com vínculos partidários e projetos político-ideológico opostos, cabe a indagação: quais as possibilidades de permanência das bases que legitimaram o Conselho do Carnaval enquanto fórum significativo de participação e decisão acerca do carnaval?

Com as suas bases institucionais bastante consolidadas é pouco provável a anulação deste espaço de poder social. O Conselho deve permanecer na nova gestão, inclusive porque há fortes interesses econômicos em jogo, de quem, de fato, faz a festa. Os setores, especialmente os empresariais, que conquistaram fatias importantes de poder de decisão acerca dos rumos da festa e, consequentemente, um maior controle sobre algumas externalidades relacionadas aos seus negócios, dificilmente vão abdicar deste espaço. No entanto, é impossível prever as possibilidades de alteração dos limites de participação e atuação do Conselho no futuro, ou o tipo de articulação que se dará entre este e a administração municipal.

\section{Conclusões}

A busca de uma racionalidade entre governabilidade e governança urbana se revelou durante a campanha municipal para eleição do prefeito da cidade em 1992, através de dois desafios básicos: o combate às desigualdades sociais e a construção de uma nova hegemonia política, através de uma luta pela autonomia do Município. O fortalecimento do poder municipal, debilitado e desmoralizado no governo anterior, sem perfil políticoideológico claro, com forte traço clientelista e comprometimento com 
Anete Brito Leal Ivo, Élvia Miriam Cavalcanti Fadul e Florence Heber

interesses privados, assentado numa cultura de subserviência e dependência administrativa do governo estadual, aparece como principal eixo político nesse projeto de gestão.

No entanto, a fragilidade da arquitetura política da coligação eleitoral, a inserção do prefeito eleito no PSDB às vésperas do pleito municipal, após negociação com o PC do $\mathrm{B}$ e a falta de um programa de governo detalhado e pactuado com os aliados, afetam a base de sustentação do executivo municipal e desencadeiam uma crise política no governo. Nasce, assim, o projeto de governo desta gestão, em meio a uma crise de governança profunda, ampliada pela grande expectativa popular de atendimento de demandas sociais historicamente insatisfeitas e agravada pelo quadro de debilitação total das finanças municipais.

Além disso, externamente, a prefeitura enfrentou uma oposição forte em torno de três ações articuladas: a) primeiro, através de um cerco da mídia, comandado pelo canal de maior audiência local ressaltando, continuadamente, os problemas não-resolvidos da cidade e evidenciando a inoperância da prefeitura; b) em segundo lugar, através da instauração, pelo governo estadual, de uma espécie de governo paralelo com ações em áreas de competência administrativa do município; e, por fim, c) através do não repasse de quaisquer recursos negociados para o governo municipal, senão aqueles vinculados do Fundo de Participação dos Municípios. Esta estratégia política de oposição interna e externa, construiu uma imagem de ausência e inoperancia da prefeitura, afetando a opinião pública independente e aprofundando o descrédito da população quanto ao projeto de gestão democrática.

Nesses termos, considerando-se os parâmetros definidores das condições de governança, a situação de Salvador é paradoxal. O sucesso e o reconhecimento internacional de alguns projetos ${ }^{11} \mathrm{e} o$ êxito de outros, ${ }^{12}$ não foram suficientes para mudar o sentimento disseminado de ineficácia política do aparelho municipal. Ademais, a segmentação do espaço urbano dificultou a percepção de resultados obtidos com políticas sociais em áreas periféricas ficando, para a opinião pública, a marca da inoperância e do abandono da cidade, refletida na falta de conservação das vias públicas, no aumento da indigência e da mendicância infantil, do comércio informal, na falta de policiamento e de segurança pública. As estratégias do executivo municipal para consolidar uma posição independente do governo esta- 
dual e sobrepor-se às pressões dessa arena política criando uma base de apoio popular, tiveram alcance restrito, limitado às áreas atendidas por programas sociais específicos, afigurando-se insuficientes para atenuar os efeitos dos condicionamentos da mídia sobre a formação da opinião pública.

\section{Notas}

${ }^{1}$ Brasil tem hoje um perfil eminentemente urbano com $75,47 \%$ da população vivendo nas cidades.

${ }^{2} \mathrm{O}$ conceito de governança local, ou seja, a "capacidade de ação do Estado na implementação de políticas públicas e na consecução de metas coletivas", compreende: a ampliação da participação da comunidade pelo reconhecimento dos direitos da cidadania; o fortalecimento de uma relação democrática entre o governo municipal e a sociedade civil; e o aumento da eficiência burocrático-administrativa, numa perspectiva de uma maior participação no processo decisório. (Coelho e Diniz 1995:4).

${ }^{3}$ Que só fica pronto um ano após o início do mandato.

${ }^{4}$ Entendida, aqui, como a "condição sistêmica mais geral sob a qual se dá o exercício do poder de uma dada sociedade" (Coelho e Diniz, 1995).

${ }^{5}$ Bairro da Paz (antiga Malvinas) na Avenida Paralela e Novos Alagados, voltado para conter a ocupação sobre as águas da Baía de Todos os Santos, na região Suburbana.

${ }^{6}$ Articulando COHAB (Habitação), SEMADE (Meio-Ambiente), SEMIM (Infra Estrutura), SMS (Saúde), LIMPURB (Limpeza Urbana) e AR- XVI (Administração Regional).

${ }^{7}$ A exemplo da Feira de São Joaquim, da área da Piedade/São Bento/ Praça Castro Alves, do Comércio e da Barra, entre outros.

${ }^{8}$ As administrações anteriores assinaram contratos com fornecedores e empreiteiras sem disponibilidade de caixa, para serem pagos, à médio prazo, à medida em que houvessem recursos nos cofres do tesouro. Através de mandato judicial, as empreiteiras com as quais a Prefeitura contraiu este tipo de dívida seqüestravam das contas bancárias do município o que lhes era devido, à cada repasse de recursos feito pela União. Não havia controle desta dívida, nem dos valores retidos pelos interessados. 
${ }^{9}$ Uma dívida de longo prazo (contratada no período 1985-1992), uma dívida de curto prazo (contratada mediante antecipação de receita com juros elevados) e uma dívida junto a fornecedores e fundos sociais.

${ }^{10}$ Ver Mensagem de encaminhamento do Projeto de Lei Orçamentária Anual do Município para 1997 à Câmara de Vereadores.

${ }^{11}$ O "Programa Cidade-Mãe" que recebeu prêmio da UNESCO.

${ }^{12}$ Especialmente a gestão do Carnaval, entre outros como os programas de engenharia de tráfego, a política de saúde do município, garantidos através da mobilização de amplos setores da sociedade, empresariado incluído.

\section{Referências Bibliográficas}

COELHO, M. e DINIZ, E. Governabilidade, Governança Local e pobreza no Brasil. Rio de Janeiro, Projeto GURI/IUPERJ/ Universidade Toronto, 1995, (mimeo).

COSTA, L. A. Um Salto Planejado. Revista Análise e Dados - Carnaval. Salvador: CEI, SEPLANTEC, v. 5, n. 4, p. 5-11, mar. 1996.

GIACOMONI, James. A comunidade como instância executora do planejamento: o caso do "orçamento participativo" de Porto Alegre. Dissertação de mestrado, PPGA-UFRGS, Porto Alegre, 1993, 152 p. GOVERNO MUNICIPAL, CPM/PMS. Plano Diretor de Desenvolvimento Urbano da Cidade do Salvador. Termos de Referência. Salvador, agosto de 1993, 39p.

GOVERNO MUNICIPAL, PMS. 3 Anos de Governo: a estratégia da igualdade rumo ao século XXI. Mensagem do Prefeito à Câmara de Vereadores, Salvador: 1996, 31p.

GOVERNO MUNICIPAL, PRODAE/PMS. Plano Estratégico da Administração Municipal. Salvador, 1994, 46 p.

GOVERNO MUNICIPAL. Lei 3.525/85. Plano Diretor de desenvolvimento Urbano de Salvador, dez. 1985, 133p.

GOVERNO MUNICIPAL. Lei n. 3.688/86. Dispõe sobre as Administrações Regionais.

LEAL IVO A. et alli. Governabilidade e Governança Urbana: o caso de Salvador. CRH/UFBA-IUPERJ/Projeto GURI/Universidade de Toronto. Salvador: 1997, 197p.

LOYOLA, E. e MIGUEZ, P. Lúdicos Mistérios da Economia do Carnaval 
Baiano: trama de redes e inovações. Revista Análise e Dados - Carnaval. Salvador: CEI, SEPLANTEC, v. 5, n. 4, p. 45-55, mar. 1996.

MELO, M.A. "Governance" e reforma do Estado: o paradigma agente $x$ principal. Revista de Serviço Público. Brasília: no 47, vol.120, n. 1. jun./ abril 1996, p 67-82.

RIBEIRO, Carlos A. C. \& SIMON, Walter T. Práticas Orçamentárias participativas: um estudo de caso das prefeituras paulistas. Rev. de Adm. Públ. Rio de Janeiro, 27(1)28-46, jan./mar. 1993.

SANTOS R. S. e BARRETO Filho O. Dinamica do Desequilibrio Fiscal de Salvador. Organizações \& Sociedade. Salvador: Escola de Administração da UFBA, 1996. 